Session Number: 2531

\title{
Observations on Benefits/Limitations of an Audience Response System
}

\author{
Stephen E. Silliman and Leo McWilliams \\ 257 Fitzpatrick Hall \\ College of Engineering \\ University of Notre Dame \\ Notre Dame, IN 46556 \\ Silliman.1@nd.edu \\ Mcwilliams.3@nd.edu
}

\begin{abstract}
The audience response system (ARS) used in this study integrates fully into existing presentation software and has been applied in a range of settings from high-school presentations, to interrogation of a large freshman engineering class, to guided equation development and case studies in a senior class in groundwater, to assessment of learning objectives and outcomes. The ARS allows real-time feedback to the students, as well as detailed demographic and studentspecific response summaries. Through application in these settings, a number of strengths and weaknesses of the ARS have been identified for use in engineering curricula:

-1- Students report that derivations and long lectures are more interesting, -2- Student retention was improved in a freshman engineering course, in part due to feedback provided the student via the ARS, -3- The faculty member is provided with immediate feedback to guide lectures,

-4- Responses allow monitoring of individual students,

-5- Demographic comparisons and assessment of outcomes are routinely available for analysis, and

-6- High-school students were impressed with the technological sophistication of the system. Among the weaknesses of the ARS are:

-1- Some students have commented that the ARS unnecessarily slows lectures,

-2- Some students have indicated a level of intimidation via the immediate response required with the ARS,

-3- In one class, weak students were inadvertently "left behind" due to the more advanced lectures,

-4- There is an increased potential for technology glitches, and

-5- Distribution and collection of the hand-held units must be managed to minimize the impact on class time.
\end{abstract}

While care must be taken to avoid over dependence and overuse of an ARS, it is observed that an ARS can significantly improve the learning environment and ability to assess student learning. The ARS is also a valuable tool for assessment of course and curriculum outcomes, with potential for rapid delineation of outcomes by demographic groups. 


\section{Introduction}

The College of Engineering at the University of Notre Dame has investigated the use of an audience response system (ARS) in a variety of educational settings. These investigations have been conducted to study the effectiveness, strengths and weaknesses of the integration of response technologies in various educational initiatives. Among the initiatives studied are use of the ARS: (i) in a large freshman engineering course, (ii) in a senior/graduate technical course (groundwater hydrology), (iii) as a means of rapidly surveying large groups of students to assess learning objectives and learning outcomes, and (iv) within a high-school outreach initiative where it was anticipated that student interest and attention span would be highly variable.

The goals of the assessment of the ARS included:

- Delineation of major strengths and weaknesses of the ARS in each of the above settings,

- Evaluation of student response to the use of the ARS, and

- Identification of situations in which the ARS significantly benefits (or hinders) the educational initiative.

\section{Prior Studies of ARS In Engineering Education}

It has been recognized that students learn much more efficiently and effectively in a learning environment that includes active student-student and student-faculty interaction. This was recognized a decade or more ago by a number of authors who studied the redesign of the classroom (see, for example, Cohen ${ }^{1}$ for discussion and review of this early material or $\mathrm{Chen}^{2}$ for discussion of recent issues related to use of technology in the classroom).

More recently, a number of authors have discussed ways to improve the classroom environment through individual and group activities integrated into the learning environment. $\mathrm{Kumar}^{3}$, for example, introduces "structured interactive sessions" (SIS) into the learning environment, arguing that the SIS increase the exchange of ideas among teachers and students, thus enhancing the value of the lecture material.

Zurita et al. ${ }^{4}$ studied two collaborative learning environments and argued that introduction of a means for student response, in this case handheld computers, substantially improves the learning experience. Similarly, other authors ${ }^{5,6}$ have discussed the value of integrating computer and information technologies into the classroom. Utilizing somewhat simpler technology, Kellum et al. ${ }^{7}$ demonstrated the value of encouraging student engagement in lectures through use of student-response cards. These authors were able to demonstrate that use of the response cards increased student participation in the classroom, improved student retention of material (as measured by performance on quizzes), and increased student satisfaction with the learning experience.

Interestingly, not all authors conclude that the introduction of information technologies into the classroom will lead to an enhanced educational experience for the student. Duncan ${ }^{8}$, for

"Proceedings of the 2004 American Society for Engineering Education Annual

Conference \& Exposition Copyright@2004, American Society for Engineering 
example, concluded that in a side-by-side comparison of multiple sections of the same college course, use of information technologies in selected sections did not significantly improve student performance. While not suggesting that technology was inappropriate in given settings, Marcellus and Ghrayeb ${ }^{9}$ argue that the blackboard environment may still represent the optimal environment for lectures based strongly in problem solving. As will be noted in the discussion portion of this paper, our studies, although illustrative of the substantial potential for positive impact of technologies on the classroom environment, do support some of the cautions addressed by these other authors.

Review of this prior literature illustrates that, when properly utilized in the classroom environment, information technologies, particularly systems designed to elicit student responses during lectures, can have a significant positive effect on the learning experience. Moreover, there is evidence available in the literature that the next generation of educators is becoming more technologically sophisticated and eager to apply information technologies. Marra et al. ${ }^{10}$, for example, demonstrated this through study of undergraduate education students who were enrolled in a course on classroom technologies. One of the outcomes of the analysis of student essays by these authors was the conclusion that the students who were exposed to the use of technologies in the classroom were both more likely to envision how these technologies could be used to improve the classroom environment and more supportive of the possible use of this technology. It may be concluded from this literature that continuing study of possible applications of information technology, particularly with respect to increasing student engagement in the lecture environment, is warranted.

\section{The Technology Used In This Study}

The work discussed herein is based on two versions of hand-held response units (one is an infrared unit whereas the second is a radio-frequency unit ) in combination with TurningPoint ${ }^{\mathrm{TM}}$, a software package that allows recording and interpreting the response from the hand-held units (Turning Technologies LLC, Youngstown, OH 44503, www.TurningTechnologies.com). The radio frequency units provided up to 120 individual responses (expandable to 1024) with a central receiver communicating (in real time) the responses into the software. These were the more versatile of the two units we tested as they did not require line-of-sight between the handheld unit and the receiver, allowed multiple responses per unit (per question), and provided visual confirmation on the unit of the response selected. The infrared units were considerably less expensive per unit ( $\sim \$ 30$ per unit versus $\sim \$ 350$ per unit for the radio frequency units) and considerably more convenient (smaller size). However, the receiver for the infrared unit required direct line-of-sight for each unit, thus limiting application in large or crowded classrooms. Multiple receivers can be used to reduce the impact of the requirement of line-ofsight. The system at use at Notre Dame also allows mixing of both the radio frequency and infrared units in the same session.

Within the current application, the University owns all units and the units are distributed during class. Other ARSs are available for which the individual cost is low enough that students can purchase individual units for use throughout their curricula. It should be specifically noted that this manuscript is not intended to suggest that one particular technology is better or worse than any other. Rather, the focus is on the application of the ARS. It must be noted, however,

"Proceedings of the 2004 American Society for Engineering Education Annual

Conference \& Exposition Copyright @ 2004, American Society for Engineering Education" 
that at the time of writing this manuscript only a limited number of vendor hand-held units have been integrated into the TurningPoint ${ }^{\mathrm{TM}}$ software. Further, as noted below, radio-frequency units appear to be more flexible for application in large classes, or in crowded classrooms where lineof-site issues may be a significant handicap to use of infrared units.

The TurningPoint ${ }^{\mathrm{TM}}$ software is fully integrated into PowerPoint ${ }^{\circledR}$. This software allows addition of demographic or question slides in a fashion nearly identical to the addition of a standard PowerPoint ${ }^{\circledR}$ slide. Responses can be collected and displayed in a number of formats, thus providing substantial flexibility in preparation of a presentation. During presentation, the designer is provided with the choice of whether to graphically display responses in real time for viewing by the students, or to collect responses without display to the students. Following presentation, the designer is provided a number of options for analysis of the data collected through Excel $^{\circledR}$ spreadsheets.

\section{Assessment of Impact}

A number of assessment tools were applied to the analysis of the impact of the ARS. These include:

- Student course evaluations.

- Student retention and degree of satisfaction with the freshman engineering course.

- The value of the demographic comparisons for curriculum assessment.

- Direct student surveys regarding the ARS.

- Course material covered and mastered in the senior/graduate course.

\section{Application in Freshman Engineering Course}

The College of Engineering has required a two-semester freshman engineering course for the past four years. This course has been described and evaluated in prior ASEE publications (e.g., Pieronek et al. ${ }^{10}$; Brockman et al. ${ }^{11}$ ) and will therefore only be outlined herein. The course involves four projects over the two semesters. Each project, or module, is based on a series of learning objectives that are addressed through a series of lectures, activities in a hands-on learning center, and review/discussion during recitations. The lectures are addressed to the entire class - approximately 370 students start the fall semester. The learning center and recitations are addressed to groups of 25-30 students.

Assessment of the first semester course during the 2002/3 academic year indicated three significant issues to be addressed during the 2003/4 academic year. The first issue was significant loss of students during the first project, a project oriented towards the prediction of flight dynamics, but containing (during the 2001/2 and 2002/3 academic years) a significant

\footnotetext{
"Proceedings of the 2004 American Society for Engineering Education Annual Conference \& Exposition Copyright @ 2004, American Society for Engineering Education"
} 
component of programming. During the 2002/3 offering, for example, 39 students failed to complete the first semester course. This low rate of retention was further exacerbated by a significant gender bias with women dropping at significantly higher rates than men.

The second issue was student perception of differential skill sets among the students in terms of computer programming. A number of students who dropped the course, as well as a number of students who completed the first semester but did not continue into the second semester, indicated that they felt that the vast majority of other students within the course had superior programming skills and these students had a significant advantage in terms of completing the projects.

The third issue was student assessment that the lectures were of limited value with respect to the content of the course. This assessment was dramatically reflected in the low attendance numbers observed during lectures in the latter portion of the course (often falling below 50\%).

The details of our reaction to these issues are detailed in a companion paper at this conference (McWilliams et al. ${ }^{12}$ ) and a thorough discussion of the gender issues impacting this course are contained in another companion paper (Pieronek et al. ${ }^{13}$ ). Within the present discussion, efforts to utilize the ARS to directly address the latter two issues (and indirectly address the first issue) are presented.

\section{The Questions}

The goals of the use of the ARS in this setting were to: (i) increase student engagement in the lectures, (ii) increase the value of the lectures to the learning process, (iii) provide the students with an anonymous means of providing feedback to the lecturer, and (iv) provide students with direct indications of their level of accomplishment relative to the accomplishments of their fellow students. These goals were approached through a series of demographic and technical questions, the responses to which were collected anonymously using the radio-frequency ARS during lectures.

With respect to engagement and increasing the value of the lectures, one of the objectives of using the ARS was to keep the students awake and active during lectures. Hence, students were asked to respond to a series of questions, during the lecture, within groups of 3-4 students.

Typical questions utilized were of a form similar to: "Within your group, what do you think will be the most important area(s) of contribution in engineering in your lifetime?", "How do we get total work, W, from the previous equation for dW?", or "For your project, are you going to need to solve $\int d W=\int_{s 1}^{s 2}(\|F(x)\|)(\cos (\theta(x)) d\|x\|$ ?". These questions were followed by a series of multiple-choice answers, time for students to discuss the questions, time for student response, display of the statistics of the student response, and discussion by the lecturer / students of the student response.

With respect to providing the students with an anonymous means of providing feedback to the lecturer and to the other students, we included questions within the lectures that addressed student learning and comfort with the material being covered. Examples of this type of question include: "How is the pace of the course so far?", "How well do you understand the goals of this

"Proceedings of the 2004 American Society for Engineering Education Annual

Conference \& Exposition Copyright@ 2004, American Society for Engineering Education" 
project?", or "What is your comfort level with the computer work so far?" As discussed below, the responses to these types of progress questions were very illustrative to both the lecturer and the students.

\section{Interpretation of the Responses and Impact on the Course}

Overall time required for response to the questions asked during lectures averaged approximately 2 minutes (including presentation of the question, student discussion, response by the students, regain of relative quiet in the lecture hall, and presentation of the results). The responses were presented to the students in graphical form similar to that shown in Figure 1. Overall, student response to an ARS question was active with substantial discussion among the students, response from essentially every ARS unit, active discussion of the resulting response statistics, and high attendance at the lectures throughout the fall semester of 2003. In many cases, visual presentation of the summary of responses elicited expressions of surprise from the student body. This was noted in particular with respect to questions regarding student comfort level with the pace or content of the course material,

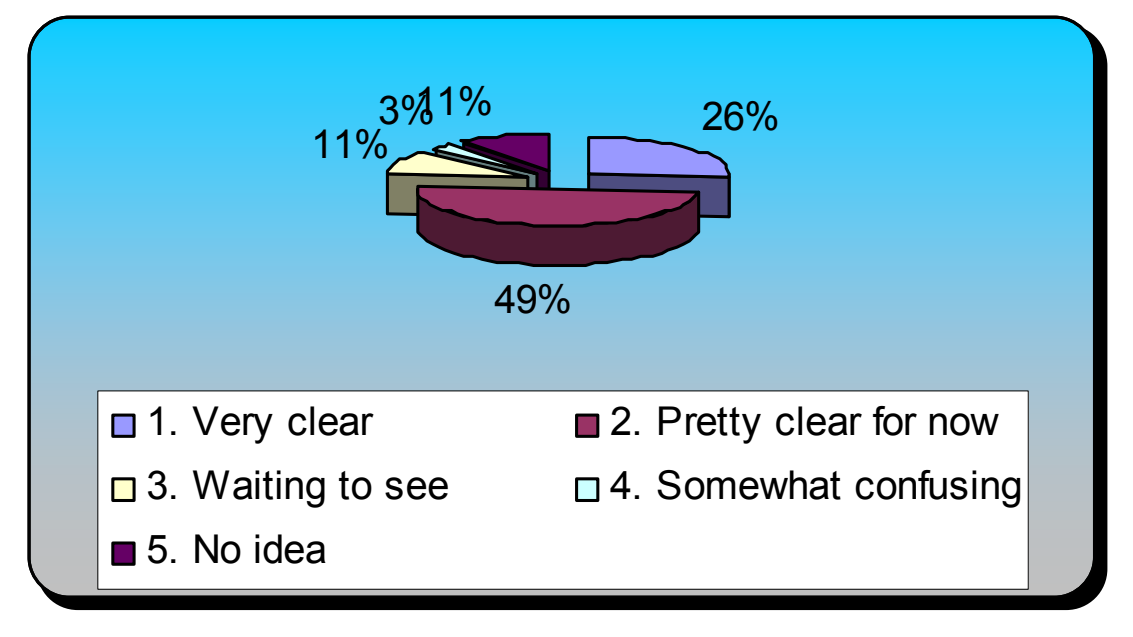

Figure 1: Typical response screen obtained during lecture. Results presented here are to the question, "How well do you understand the goals of this project?"

As noted above, questions were directed both at technical content of the course and student satisfaction with course content and pace. While the technical questions were observed to be of substantial value with respect to keeping the students engaged, the questions related to student satisfaction were of particular value both to the lecturer and to the students in gauging the pace and content of future course materials. The results in Figure 1, for example, provided both the lecturer and the students with a direct indication that the students were generally comfortable with the project material as presented, thus allowing a slight increase in pace and technical difficulty of the material presented.

Another sample question, designed specifically to provide the students with a class-wide self assessment of their computer skills, was "what is your comfort level with the computer work so far?" Queried multiple times during the first project in the fall of 2003, the students were asked to pass around the response units such that each student could respond for himself/herself. The

\footnotetext{
"Proceedings of the 2004 American Society for Engineering Education Annual Conference \& Exposition Copyright@ 2004, American Society for Engineering Education",
} 
resulting percentage responses received approximately midway through the project are shown in Figure 2. Interestingly, these results demonstrate what had been anticipated by the faculty involved in the course, namely that there is a wide range of comfort with computer programming among the students within the course.

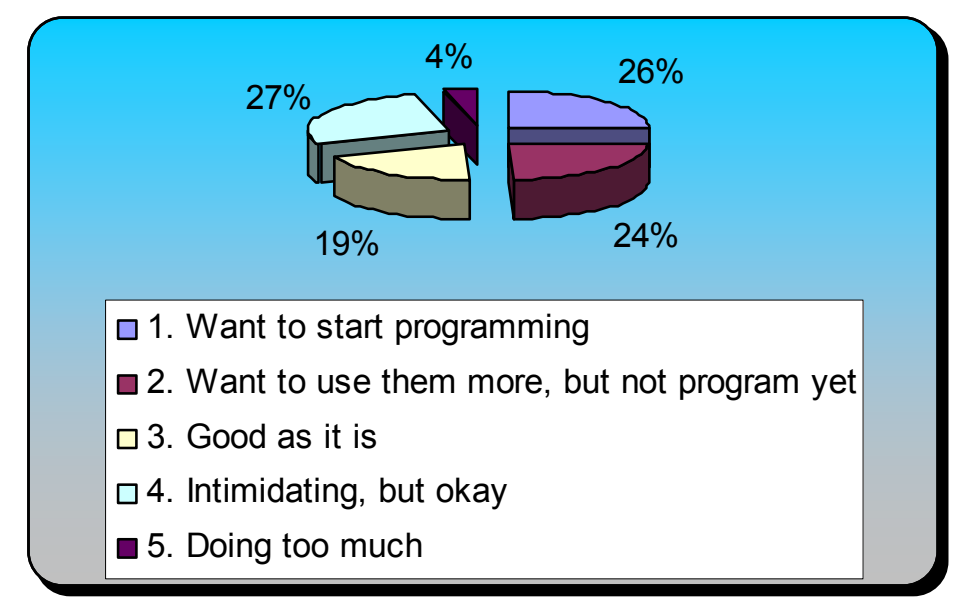

Figure 2: Student response to the question "what is your comfort level with the computer work so far?" The response demonstrated to both the faculty and the students the tremendous diversity of computer skills present within the student population.

Providing students with immediate results on student satisfaction, particularly the question represented in figure 2 , is believed to be in part responsible for significantly higher retention of students in the fall semester of 2003 (whereas 39 students dropped the course during the fall semester of 2002, only 5 students dropped the course during the fall semester of 2003). Specifically, a significant number of the students dropping the course in the fall of 2002 (as well as students remaining within the course) indicated that they felt that, relative to other students, their computer skills were inadequate to compete in engineering. While a reduced focus on computer programming contributed significantly to the higher retention in 2003, it is believed (based on informal interviews with students) that providing the students with a direct measure of the range of skills present in the student population also allowed students to remain more comfortable with their individual skill sets, thus feeling more comfortable within the course.

\section{Value of the ARS in the Freshman Course}

The ARS appeared to have three significant positive impacts on the freshman engineering course. First, the students remained more involved in the lectures and, thereby, attendance at lectures during the fall semester of 2003 was substantially higher, throughout the semester, than observed in the fall semester of 2002. As a result, the lecturers had greater opportunity to reach a wide student audience.

Second, the students were provided with multiple opportunities to informally gauge their progress on the projects (through both technical and satisfaction inquiries) relative to their classmates. As a result, the faculty involved in the course during the fall semester of 2003 heard very little concern from the students regarding being overwhelmed with the workload or relative

\footnotetext{
"Proceedings of the 2004 American Society for Engineering Education Annual Conference \& Exposition Copyright@ 2004, American Society for Engineering Education",
} 
skill sets among the students relative to programming. This was a dramatic change from the student comments to the faculty during the fall semester of 2002.

Third, the ARS provided substantial feedback to the faculty regarding the degree of understanding of course material among the students, the skill sets of the students (and the diversity of this skill set among the students), and the development during the project of skill sets of the students. While much of the information garnered in this regard was consistent with hypotheses put forth by faculty previously involved in the course, developing direct evidence of student diversity and development provides needed support for proposed modifications to the course.

Student response within this course to the ARS has been overwhelmingly positive. The students have noted that the units allow active interaction with the lecturer despite the large lecture hall and provide multiple opportunities for active learning during the lecture. They also note that the units provide a welcome change during extended lectures, particularly those involving derivations.

It should be noted that, within this application, no effort was made to tie the individual response units to particular groups of students. Hence, all responses were anonymous. The impact of anonymity is discussed below.

\section{Application in a Senior Technical Course}

A course in Groundwater Hydrology is offered to seniors and first-year graduate students in the curricula in Civil Engineering and Geological Sciences at Notre Dame (the course is required of seniors pursuing either the environmental geoscience degree or the environmental tract of the civil engineering curriculum; it is optional for seniors in the structural tract and for first-year graduate students). The ARS was used in this course to provide an active guide for classroom discussion of concepts and derivations and, during the most recent offering of the course, to provide the lecturer with a direct measure of the progress of individual students. This latter application was made possible by tying specific hand-held response units to specific students during the fall, 2003, semester.

\section{The Questions}

All questions asked via the ARS in this course were technical in nature. They were applied at two levels. The first level involved review, often conducted early in a lecture, of assigned reading and prior lecture material. This level of ARS provided immediate feedback to the lecturer regarding the knowledge/preparation level of the students, thus allowing the lecturer to accelerate through material mastered by the students and to spend more time on concepts not understood by the majority of the students.

The second level involved ARS questions presented as part of discussion of difficult derivations or concepts. This level of question challenged the students to remain attentive during these discussions. Further, this type of question helped to guide the students in asking appropriate questions during derivations and discussions.

"Proceedings of the 2004 American Society for Engineering Education Annual

Conference \& Exposition Copyright @ 2004, American Society for Engineering Education" 


\section{Interpreting the ARS Responses}

As indicated above, one of the uses of the ARS in this technical course was to measure student understanding of course material. Figure 3 shows the student responses to the question, asked at the beginning of a lecture on the groundwater flow equation, "The initial differential equation is based on which of the following assumption(s)?" This diverse response (the correct answer being "isothermal conditions") was accepted by the lecturer as evidence that the students did not correctly understand the concepts presented in the previous lecture on the flow equation. Thus the lecture was refocused on the assumptions underlying the equations being developed.

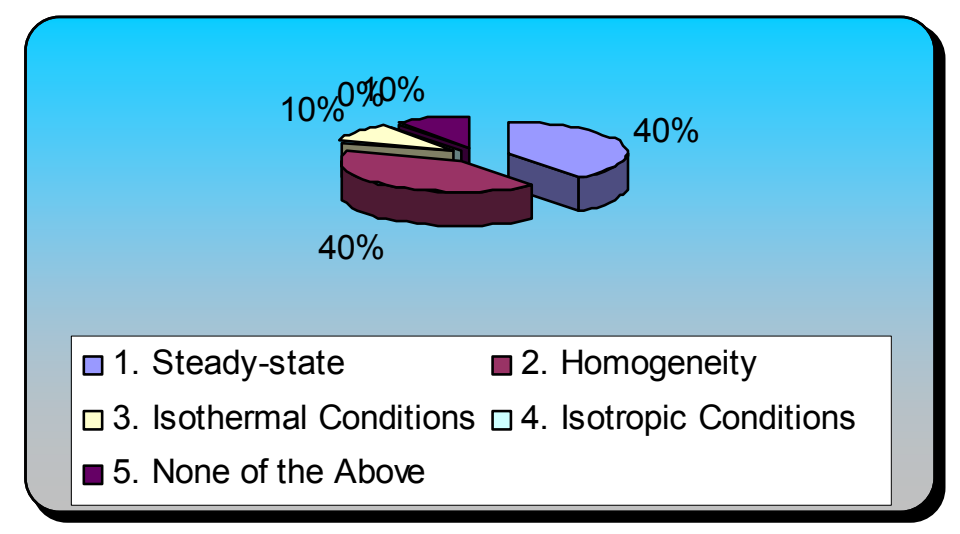

Figure 3: Student response to the question "The initial differential equation is based on which of the following assumption(s)?"

The ARS was first applied to this course in the 2002/3 academic year. During this initial application, the response units were distributed randomly such that responses were anonymous. The result of this application was that the course covered more material at a deeper level. This result was considered a positive result relative to application of the ARS during the course of the semester. However, it became apparent during the semester that by accepting responses anonymously, the lecturer was unable to identify individual students who were consistently answering the questions incorrectly. Hence, while the lecturer considered the students to have mastered the material when approximately $90 \%$ of the responses were correct, he did not have the opportunity to observe that the same students were consistently in the $10 \%$ who were incorrectly responding to the questions. These students performed poorly on the first exam and thus substantial remedial effort was required to bring them up to speed on the course material.

Based on this experience with the ARS, students enrolling in this course in the fall of 2003 were assigned numbered response units. As a result, student responses could be monitored over time to determine the mastery of the material by individual students. During the period of the fall semester of 2003, monitoring of individual responses provided the lecturer with evidence required to identify one student who, because of difficulty in communicating in English, had substantial difficulty with rapid response to multiple-choice questions, thus allowing the lecturer to address this issue with the student prior to the first written exam. It also provided evidence that a second student was struggling with the material, allowing the lecturer more insight into this student's skill set when the student sought advice regarding whether to drop the course. 


\section{Reaction to the ARS System}

Student response to the ARS within the technical course was very positive on the whole, but there were isolated negative reactions to the ARS. A number of the seniors expressed very positive response to the system, including comments that the ARS provided:

- Stimulation to remain focused on detailed derivations,

- A direct measure of the degree to which material was mastered by the student, and

- A "change of pace" during lectures.

In contrast, at least three negative comments have been received over the past two offerings of the course, including:

-The ARS unnecessarily slowed the pace of the lectures,

- The need for each student to respond in real time was uncomfortable to at least one graduate student, and

- The ARS allowed the lecturer to advance too quickly in lectures.

Evaluation by the lecturer regarding the amount of material covered in the course demonstrated that, while selected topics were covered in greater detail, overall the course covered approximately the same amount of material as had been covered prior to use of the ARS system. Hence, while the ARS provided the lecturer with regular feedback regarding student learning, it did not (as was hoped) provide substantial opportunity for covering a greater amount of material during the semester.

\section{Evaluation of Curriculum Learning Goals and Objectives}

The ARS was applied at the end of the 2002/3 academic year to determine the degree to which the students felt that they had achieved stated outcomes identified for the undergraduate civil engineering curriculum. Each academic class (sophomore through senior) was gathered in a classroom for a 45 minute period in which the students were presented with a series of questions, were provided with the opportunity to clarify the intent of any questions, and were then allowed to respond to each question. Results were analyzed both in terms of the overall class response and responses separated by demographic groups.

\section{The ARS Slides}

The slides were divided into demographic and question slides. Among the demographics were gender, degree of involvement in athletics, and tract pursued within the last two years of the curriculum (the students must select between environmental and structural tracts for the junior and senior years). Among the questions were inquiries regarding several of the specific learning outcomes delineated for this curriculum. Unlike the other applications of the ARS, the student 
responses were not displayed to the students following each question. This option was selected in an attempt to avoid having the distribution of student responses to one question impact individual student responses to the remainder of the questions.

Figure 4 shows student response among a senior study group (10 students) to three questions. The first question (left figure) was, "Has your education at Notre Dame provided you with incentive to continue to grow as a person following graduation (e.g., through reading, professional development, activities involving learning new skills, etc.)?" The possible responses offered to the students were (N.D. stands for the University of Notre Dame): (a) "Yes, N.D. has strongly encouraged me to pursue future opportunities to grow as an individual", (b) "Yes, I anticipate that N.D. has bred within me the desire to continue to grow", (c) "I have the desire to continue to grow, but it is unclear how my education impacted this desire", (d) "No, while I have the desire to continue to grow, N.D. has probably turned me away from intellectual pursuit in the short term", and (e) "No, definitely not".

The second set of results illustrated here were responses to the question "To what degree has your ND education to date helped you in your ability to identify, formulate and execute solutions to complex, multidisciplinary problems in CE?" The possible answers were: (a) "I am well prepared to address such complex, multidisciplinary problems", (b) "I am confident that I can work with others to address such problems", (c) "With help, I can work with others in an effort to address such problems", (d) "I need more education in order to have the tools to address these problems", and (e) "I am unprepared to address complex problems in CE".

The third set of results illustrated here were responses to the statement "Your ability to present technical results in oral and written form ..." Possible responses included: (a) "Improved significantly since entering ND", (b) "Improved a little bit since entering ND", (c) "Has not changed since entering ND", and (d) "Seems to have declined since entering ND".
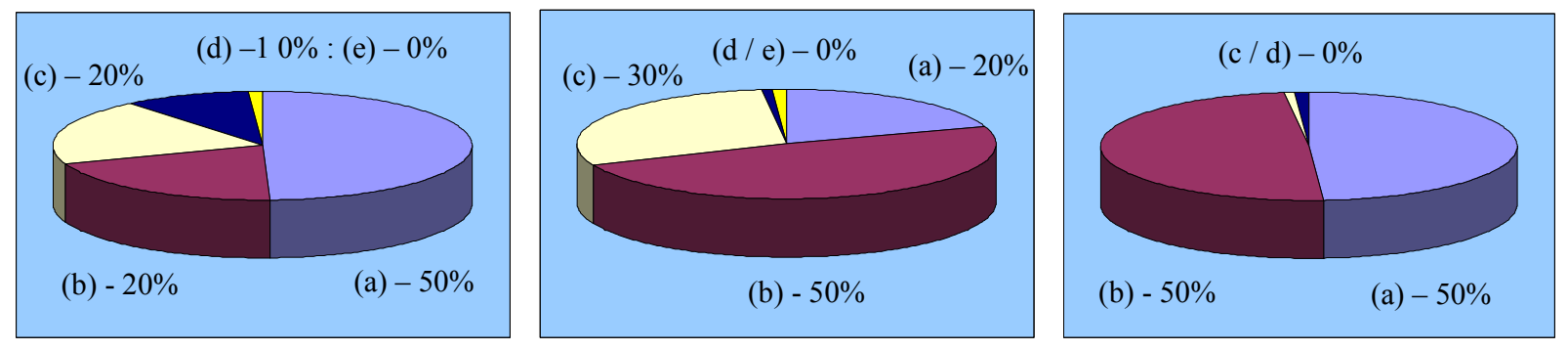

Figure 4: Illustrative results for the assessment efforts using the ARS as applied to a study group of senior civil engineering students who had completed the fall semester. In these images, light blue represents answer a, maroon represents answer b, white represents answer c, dark blue represents answer $d$, and yellow represents (where appropriate) answer e. The responses shown relate, respectively (left to right), to desire for continued learning, ability to solve complex problems, and ability to communicate.

While the student responses to each of these questions are relatively reassuring from an assessment viewpoint ( $70 \%$ in the top two categories for the first two questions and $100 \%$ in the top two categories for the third question), the point of including these responses in the present manuscript is not to analyze the program in Civil Engineering at Notre Dame. Rather, it is

\footnotetext{
"Proceedings of the 2004 American Society for Engineering Education Annual Conference \& Exposition Copyright@2004, American Society for Engineering Education"
} 
intended to illustrate the utility of the ARS in assessment. First, using the ARS and associated software provides for rapid analysis of the assessment materials both for populations as a whole (as shown here) or subdivided by demographics (not shown here due to the small study group). Second, it is believed that ARS-based assessment has the potential to be more powerful than paper-survey based assessment as the person running the ARS session can respond to student questions regarding the intent of particular questions. As a result, there is a greater opportunity for all students to respond to the connotation intended by the person preparing the question. It is anticipated that this use of the ARS will be expanded to the entire student population in Civil Engineering and Geological Sciences at Notre Dame in the spring semester of 2004.

\section{Application in a High School Setting}

The final application discussed herein was within a freshman/sophomore history class in which a faculty member from Notre Dame was leading a discussion of life and technology in a developing country (Benin, Africa). The goals of the ARS within this setting were three fold: (i) create a level of excitement in a lecture that would commonly be considered irrelevant to this population of students, (ii) provide the students with an opportunity to become actively involved in the lecture, and (iii) gauge changes (by gender) in student perception of issues between the beginning and end of the lecture.

Results from the application of the ARS in this setting demonstrated very clearly that the introduction of the ARS within this particular school was a cause for excitement among the students. This was evidenced by the level of student involvement during each of the response periods and the student willingness to discuss the range of responses obtained. This was also evidenced by student comments included in notes received by the faculty member following the lecture.

The results also provided direct evidence of impact on student opinion through the period of the lecture. The students were, for example, asked at both the beginning and end of the lecture whether they would be interested in spending a period of time (the time suggested was 3 months) in Benin, Africa. Figure 5 shows the summary of student response at the beginning and end of the semester. These results clearly show a change in student opinion regarding visiting Benin. First, there is a clear shift from the lower two answers ("probably not" and "no way") towards the upper two answers ("gladly" and "maybe"). In addition, there is a noticeable decline in the number of male students (as contrasted with the increase in female students) responding "gladly". Hence, the professor was provided with rapid feedback regarding the short-term impact of the lecture. Clearly, follow-up analysis would be required in this case to determine long-term impact of the lecture.

The impact of the ARS was, in this case, immediate and positive. The students found the ARS to be novel and exciting and were therefore attentive throughout the 50 minute lecture. As such, the ARS allowed the faculty member to present material to an attentive audience who were ready to respond on an individual basis. Further, the ARS provided the faculty member with immediate indication of the impact of the lecture on student opinion.

"Proceedings of the 2004 American Society for Engineering Education Annual

Conference \& Exposition Copyright@ 2004, American Society for Engineering Education" 

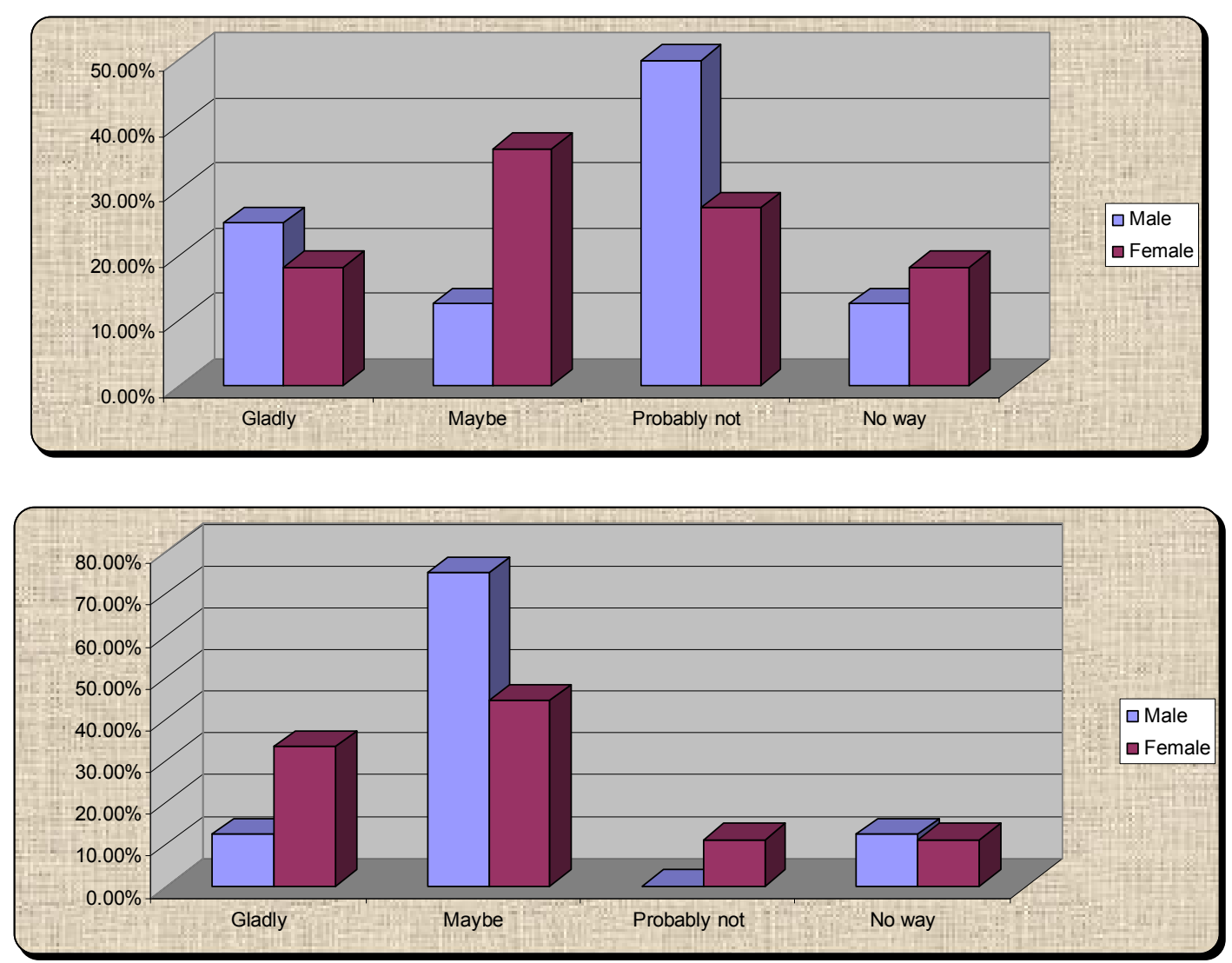

Figure 5: Comparison of student response to the question "Would you want to spend a period of time (e.g., 3 months) in Benin?" The upper result was measured at the beginning of the lecture and the lower result was measured at the end of the lecture. The shift in student opinion is apparent, including not only a general increase in positive responses to the question, but also a decrease in the number of males indicating high willingness to visit Benin.

\section{Overall Evaluation of the Utility of the ARS}

The ARS has been applied and evaluated in a number of educational environments. In general, the ARS proved to be of significant value with respect to improving the learning experience for the student and increasing the assessment information available to the faculty member. In particular, the ARS was observed to:

1. Increase the level of student engagement in all levels of courses (ranging from high school, to a large-format freshman engineering course, to a small senior technical course). In particular, students indicated that the ARS provided them with incentive to pay closer attention to lecture material so as to be prepared to respond to in-class questions.

2. Improve the retention within a large freshman engineering course (in combination with other changes to the course). It is believed, based on informal survey of the students, that 
retention was improved via increasing the student confidence in their relative skill set (computing skills and skills specific to the first project).

3. Allow monitoring of progress of individual students through tying response unit identification numbers to specific students.

4. Provide the lecturer with real-time measures of student understanding of course material.

5. Provide for rapid, detailed assessment based on responses and demographics gathered via the ARS.

Although the ARS was observed to be a powerful tool to improve the learning environment, there were a few concerns raised in this study which reflect, to a degree, concerns raised by other authors (e.g., [7],[8]). Specifically, assessment of the application of the ARS included the following negative observations:

1. Over dependence on the ARS led some students to feel that the pace of lectures was being unnecessarily slowed such that less material could be covered in any given lecture,

2. While the ARS allowed the lecturer to advance more quickly in some lectures, the overall progress observed in the senior technical course when supported by the ARS was not dramatically different (in terms of material covered - no measure of comparative student learning has been performed) than was observed in prior years without the ARS.

3. When used with anonymous assignment of hand-held units to the students, the ARS has the potential to create a greater degree of differential learning between the upper and lower quartiles of the class.

4. One student noted that the ARS was intimidating due to the requirement, during lectures, to always be prepared to produce a rapid response to questions.

5. Use of the ARS increased the technical sophistication required in lectures, thus leading to a higher probability of technical "glitches" during lectures.

6. Distribution and collection of the hand-held units had to be managed in order to minimize the impact on class-time

As noted above, while this study is based on a specific ARS (hand-held units and associated software), it is felt that the vast majority of the conclusions outlined here are system independent. Hence, it must be concluded that audience response units such as these, whether based on specially designed response units, PDAs, or lap-top computers, have substantial potential to improve the learning environment of the student and the assessment environment of the faculty member. 
References Cited

1- Cohen, EG, 1994, "Restructuring the classroom - conditions for productive small-groups", Review of Educational Research, 64(1), 1-35.

2- Chen, JC et al., 2000, "Technology in engineering education: What do the faculty know and want", Journal of Engineering Education, 3, 279-283.

2- Kumar, S, 2003, "An innovative method to enhance interaction during lecture sessions", Advances in Physiology Education, 27(1), 20-25.

3- Zurita, G, M Nussbaum, and M Shaples, 2003, "Human-computer interaction with mobile devices and services", Lecture Notes in Computer Science, 2795, 193-208.

4- Campbell, CB, and RB Floersheim, 2003, "Wireless laptops in the classroom: No strings attached?", Proceedings, ASCE annual conference, session 1620.

5- Burtner, J, and L Moody, 1999, "Increasing the use of collaborative learning techniques in an integrated economics and engineering economy course", Proceedings, ASEE, session 3657.

6- Kellum, KK, JE Carr, and CL Dozier, 2001, "Response-card instruction and student learning in a college classroom", Teaching of Phychology, 28(2), 101-104.

7- Duncan, DG, 2000, “Using computers in the classroom: A boon or bust?", Jour. Of Computer Information Systems, 40(4), 1-4.

8- Marcellus, R, and O Ghrayeb, 2003, "Effects of smart classrooms on learning and teaching effectiveness: the students' point of view”, Proceedings, ASCE annual conference, session 3557.

9- Marra, RM and AA Carr-Chellman, 1999, “Undergraduate education students' perspectives on classroom technologies: A qualitative analysis", Jour of Educational Computing Research, 21(3), 283-303.

10- Pieronek, C, L McWilliams, and S Silliman, 2003, "Initial observations of student retention and course satisfaction based on first-year engineering student surveys and interviews", Proceedings of ASCE, session 3553.

11- Brockman, J, TE Fuja, S Batill, 2002, "A multidisciplinary course sequence for first-year engineering students", Proceedings of ASCE,session 2253.

12- McWilliams, L, S Silliman and C Pieronek, 2004, "Modifications to a Freshman Engineering Course Based on Student Feedback “,2004 ASEE Annual Conference and Exposition, Salt Lake City, Utah, June 2004.

13- Pieronek, C, L McWilliams, and S Silliman, 2004, "“A Demographic Characterization of First-Year Engineering Students,” 2004 ASEE Annual Conference and Exposition, Salt Lake City, Utah, June 2004.

"Proceedings of the 2004 American Society for Engineering Education Annual

Conference \& Exposition Copyright@ 2004, American Society for Engineering Education" 
Biographical Information:

STEPHEN E. SILLIMAN is a Professor of Civil Engineering and Geological Sciences and an Associate Dean in the College of Engineering at the University of Notre Dame. His research is in groundwater and groundwater transport. He has been active for the past several years in research and educational opportunities related to water resources in developing countries.

LEO H. McWILLIAMS has served as course coordinator for the First-Year Engineering Program at the University of Notre Dame since 2001. Prior to joining Notre Dame in this capacity, he worked as a principal engineer at Honeywell International. Dr. McWilliams received his B.A. in economics, B.S.E.E., M.S.E.E. and Ph.D. from the University of Notre Dame. 